\title{
PENERAPAN METODE SOBEL UNTUK PENGUKURAN TINGGI BADAN MENGGUNAKAN WEBCAM
}

\author{
Ade Noversi Putra, Agus Basukesti, Dwi Nugraheny \\ Jurusan Teknik Informatika \\ Sekolah Tinggi Teknologi Adisutjipto Yogyakarta \\ informatika@stta.ac.id
}

\begin{abstract}
Measurement of human height is usually done with the help of others. But with the Sobel method, measurement of human height can be done alone. It can simplify the process of measuring human height. The method is a development method robert sobel using filter HPF (high pass filter) that given a zero buffer. This method takes the principle of the laplacian and gaussian function is known as a function to generate HPF. Applications designed using sobel method can be used for high menggukur an object with a small error rate. Best distance of $20 \mathrm{~cm}$ from the background to the object seen from the results of the error rate.
\end{abstract}

Keywords : sobel method, measurements of height, webcam

\section{Latar Belakang}

Untuk mengukur tinggi badan manusia memang memerlukan waktu sebentar apalagi menggunakan teknologi yang serba maju di jaman sekarang. Sebelum teknologi maju, pengukuran tinggi badan seseorang dilakukan secara manual yaitu dengan alat pengukur tinggi badan model lama menggunakan meteran yang proses pengukuran dilakukan secara langsung, dengan cara seseorang mengukur tinggi badan orang lain. Sehingga dapat diukur berapa tinggi badannya, dimulai dari telapak kaki sampai dengan kepala. Tentunya cara tersebut sangat tidak efektif karena diperlukan orang lain untuk mengukur (membaca meteran) untuk mengetahui berapa tinggi badannya.

Adanya kendala tersebut maka dikembangkanlah sebuah aplikasi pengukur tinggi badan menggunakan sistem digital dengan metode edge detection. Sehingga proses pengukuran tinggi badan menjadi lebih cepat dan tidak diperlukan lagi orang lain untuk membantu proses pengukuran. Keadaan orang yang akan di ukur posisinya berdiri.

Metode sobel merupakan pengembangan metode robert dengan menggunakan filter HPF (high pass filter) yang diberi satu angka nol penyangga. Metode ini mengambil prinsip dari fungsi laplacian dan gaussian yang dikenal sebagai fungsi untuk membangkitkan HPF. Kelebihan dari metode sobel ini adalah kemampuan untuk mengurangi noise sebelum melakukan perhitungan deteksi tepi. Metode sobel mengidentifikasi tepi dengan aproksimasi Sobel dengan turunannya. Metode ini menghasilkan atau memperlihatkan tepi pada area dimana gradiennya bernilai maksimum. 


\section{Perancangan}

\subsection{Kebutuhan Hardware dan Software}

Perlengkapan pendukung yang meliputi perangkat keras dan perangkat lunak sangat berpengaruh untuk kinerja aplikasi agar dapat berjalan secara maksimal. Oleh karena itu, sangat diperlukan untuk merancang dan menjalankan sebuah sistem aplikasi.

\subsubsection{Kebutuhan Hardware}

Hardware adalah perangkat keras (alat) yang bisa dilihat dan diraba oleh manusia secara langsung yang mendukung proses komputerisasi. Beberapa kebutuhan perangkat keras yang digunakan dalam pembuatan aplikasi Edge Detection ini adalah :

1. Hardware Yang Digunakan Dalam Membangun Sistem

1) Laptop : Dell N4030 + Intel Dual Core P6200 2.13GHz.

2) Memori (RAM) 2 GB + Harddisk 250 GB + VGA: 763 MB.

3) Mouse.

4) Kamera / Webcam

2. Kebutuhan Minimal Hardware Dalam Menjalankan Sistem

1) PC atau Laptop dengan Processor $1 \mathrm{GHZ}$ atau Lebih.

2) Kapasitas Random Acess Memory (RAM) $128 \mathrm{MB}$.

3) Hardisk dengan ruang kosong $100 \mathrm{MB}$.

4) VGA Card $32 \mathrm{Mb}$ Onboard atau VGA Card.

5) Camera atau Webcam 1,3 Mb Pixel.

\subsubsection{Kebutuhan Software}

Adapun spesifikasi software atau perangkat lunak yang digunakan dalam pembuatan aplikasi Edge Detection ini adalah :

1. Sistem operasi Microsoft Windows 7, sebagai sistem operasi yang digunakan pada komputer.

2. Borland Delphi 7, software bahasa pemrograman yang digunakan untuk pembuatan aplikasi.

\subsection{Perancangan Antarmuka Edge Detection}

Perancangan antarmuka Edge Detection adalah perancangan tampilan muka yang akan digunakan untuk pengimplementasian dari proses penghitungan citra digital obyek dengan garis tepi. Pada perancangan antarmuka sistem Edge Detection terdapat satu form. Pada Form Edge Detection terdapat lima button yang memiliki fungsi untuk memilih kamera (button perangkat), untuk mengambil gambar (button foto), untuk mencari gambar (button cari gambar), untuk mencari garis tepi (button proses), dan untuk keluar dari aplikasi (button keluar). Selain itu terdapat informasi input tampilan obyek di kamera, tampilan citra digital, ukuran pixel, hasil proses,dan ukuran latar (lihat gambar 3.8). 


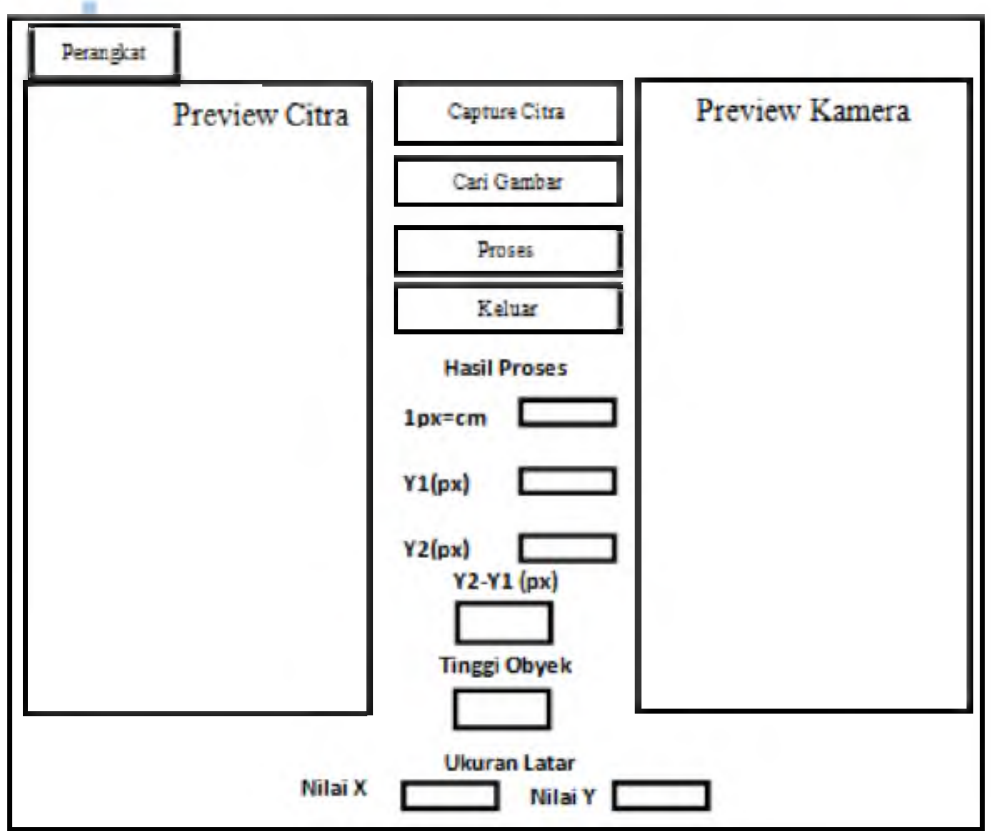

Gambar 3.9 Gambar Form Edge Detection Rancangan

\section{Pengujian}

\subsection{Proses Edge Detection Dengan Sobel}

1. Pada saat klik tombol proses maka akan secara langsung citra yang telah diinput-kan akan dikonversi ke citra grayscale kemudian dengan edge detection metode sobel untuk mendapatkan garis tepi. Hasil citra grayscale berupa citra warna keabu-abuan pada gambar 3.2, sedangkan edge detection hanya berupa garis yang cerah berwarna putih, dan mendapatkan nilai tinggi seperti gambar 3.3, dan gambar 3.4.

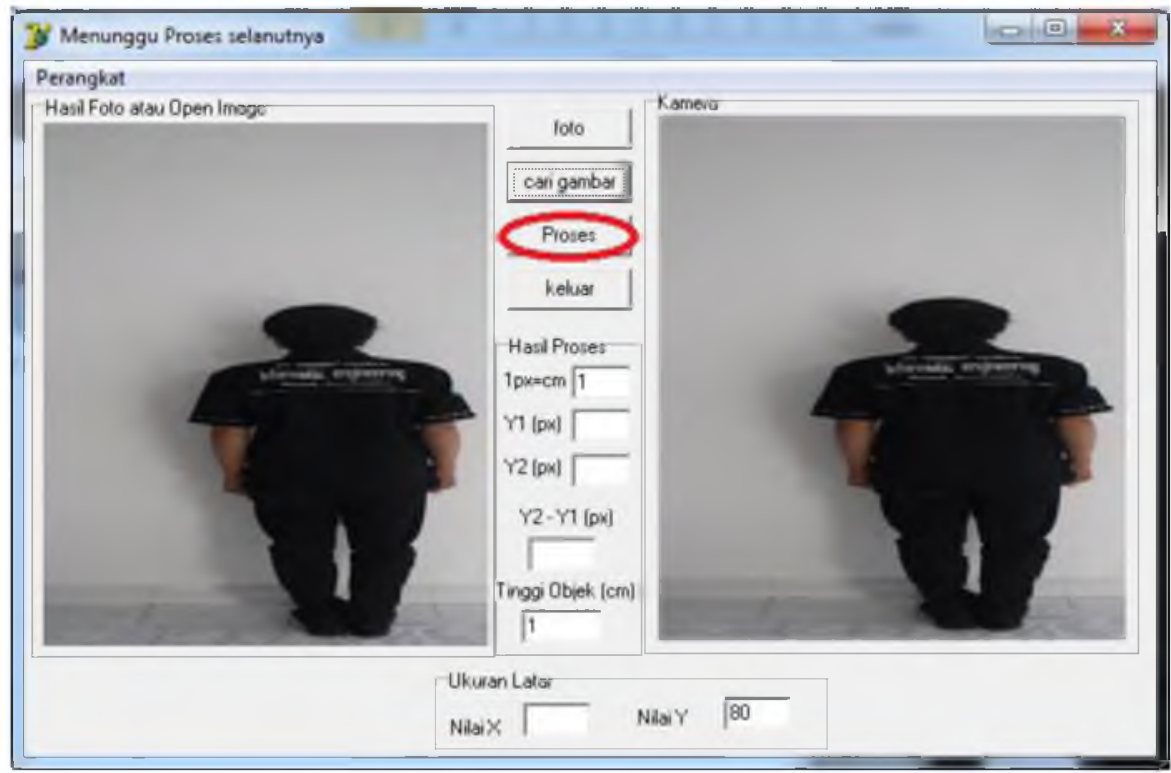

Gambar 3.1 Gambar Citra Yang Terpilih 

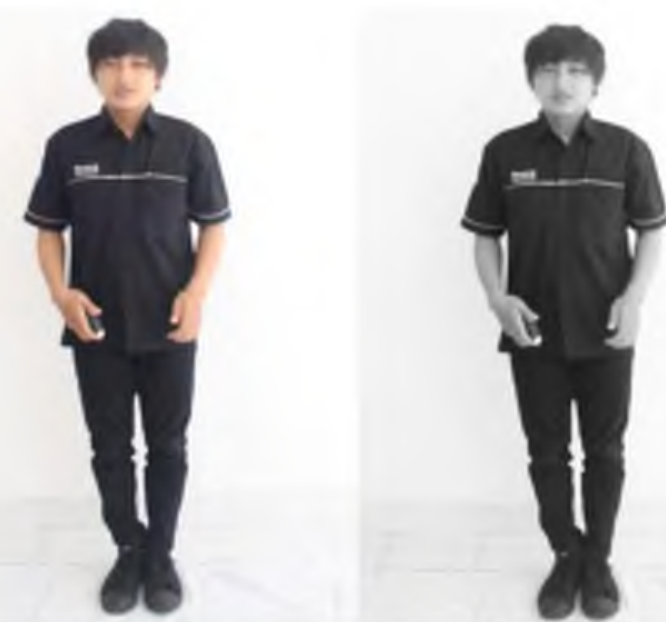

Gambar 3.2 Contoh Citra Digital Yang Dikonversi ke Grayscale

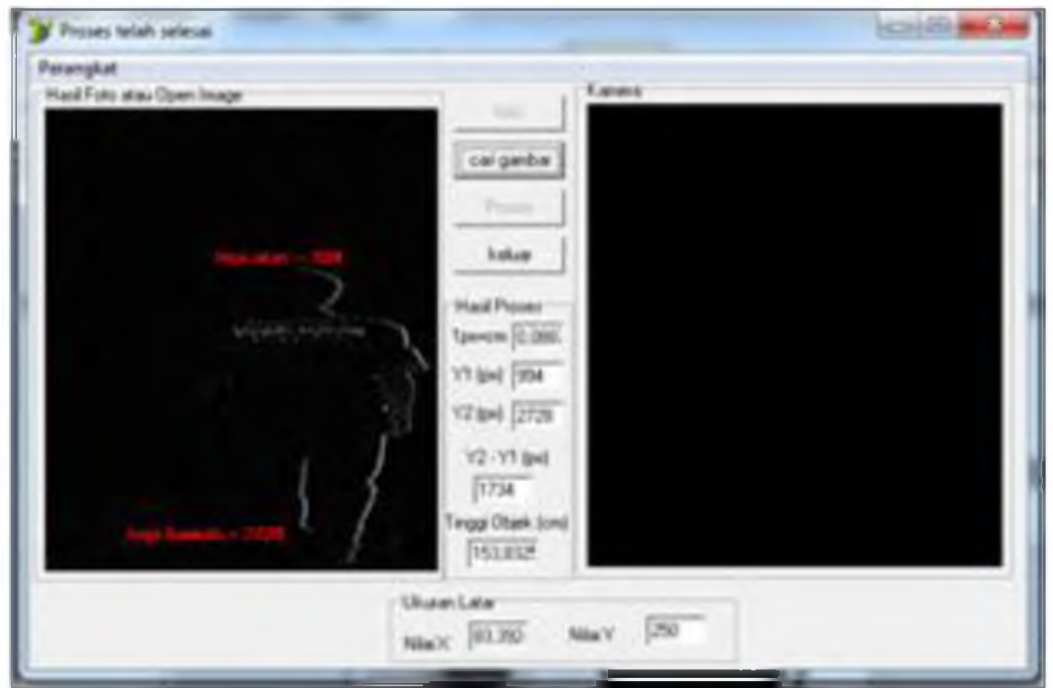

Gambar 3.3 Gambar Hasil Deteksi Tepi

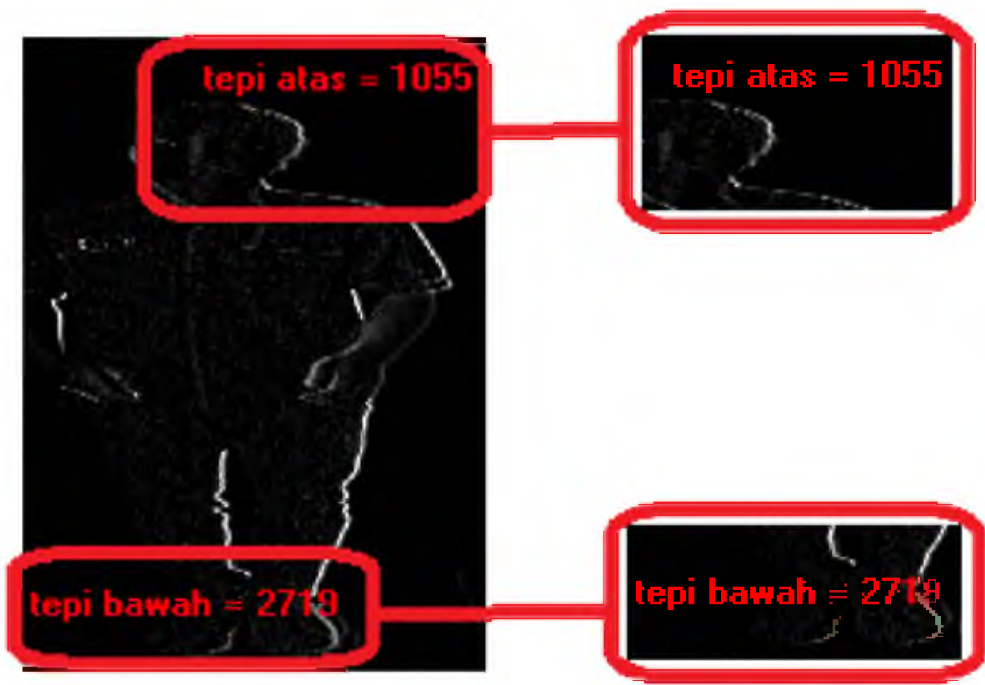

Gambar 3.4 Contoh Untuk Penentuan pixel untuk titik tepi atas dan titik tepi bawah 
Setelah garis tepi citra digital didapatkan dan tepi atas dan tepi bawah di ketahui dan dikonversi pixel ke centimeter maka akan mendapatkan nilai tinggi obyek. Berikut contoh tahapan konversi citra digital ke grayscale hingga mendapatkan hasil biner kemudian garis tepi dengan metode sobel yang ditunjukan pada gambar 3.5.

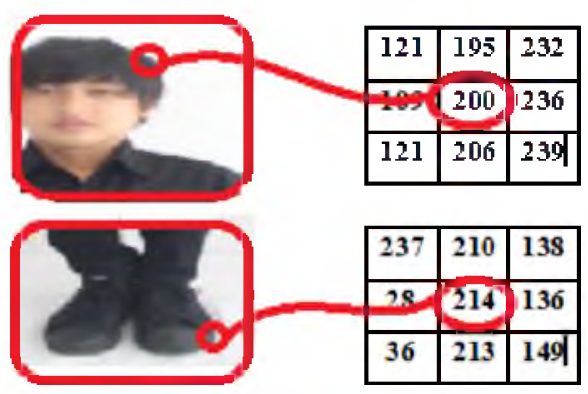

Gambar 3.5 Contoh Konversi Pixel Dalam Bentuk Matrik Grayscale

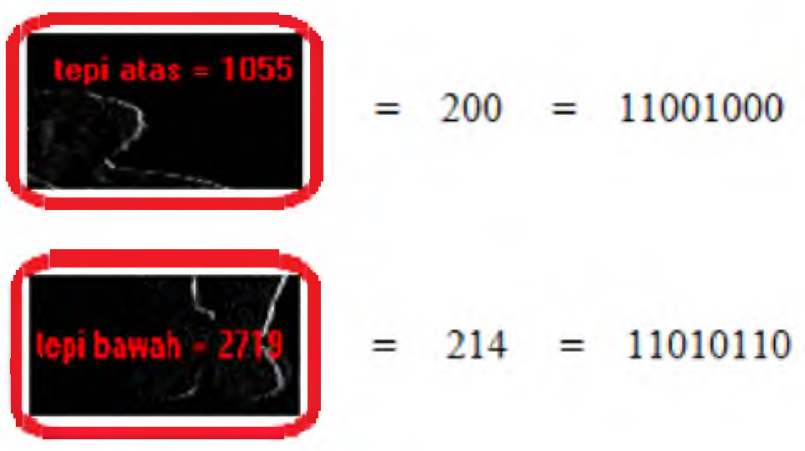

Gambar 3.6 Contoh Konversi Citra Digital Nilai Biner Menjadi Garis Tepi dengan Sobel

2. Setelah proses edge detection dengan sobel selesai, hasil citra dengan format bitmap disimpan dengan otomatis di media penyimpanan di komputer. Citra yang disimpan adalah angka-angka yang didapat dari matrik.

Mendapatkan nilai biner dari angka-angka matrik pada gambar 3.6 dengan metode sobel cara penghitungannya sebagai berikut :

Contoh : $\mathrm{f}(2.2)=214$
\begin{tabular}{|c|c|c|c|}
\hline 95 & 206 & 232 & 50 \\
\hline 121 & 237 & 210 & 138 \\
\hline 109 & 28 & 214 & 136 \\
\hline 121 & 36 & 213 & 149 \\
\hline
\end{tabular}

Gambar 3.7 Gambar Angka-Angka Dengan Format Bitmap 
Sobel

Operator Sobel horisontal

\begin{tabular}{|c|c|c|}
\hline-1 & 0 & 1 \\
\hline-2 & 0 & 2 \\
\hline-1 & 0 & 1 \\
\hline
\end{tabular}

Operator Sobel vertikal

\begin{tabular}{|c|c|c|}
\hline-1 & -2 & -1 \\
\hline 0 & 0 & 0 \\
\hline 1 & 2 & 1 \\
\hline
\end{tabular}

Gambar 3.8 Gambar Kernel Operator Sobel Horisontal dan Vertikal

Dari data gambar 3.7 dimasukkan ke dalam matriks Horisontal dan Vertikal

$$
M=\sqrt{S_{x}^{2}+S_{y}^{2}}
$$

Horisontal $=\mathrm{K} 1(x, y)=(-1 * 237)+(-2 * 28)+(-1 * 36)+(1 * 138)+(2 * 136)+(1 * 149)=\mid-$ $230 \mid=230$

Vertikal $=\mathrm{K} 2(\mathrm{x}, \mathrm{y})=(-1 * 237)+(-2 * 210)+(-1 * 138)+(1 * 36)+(2 * 213)+(1 * 149)=\mid-184$ I $=184$

Maka $\mathrm{f}(2,2)$ bila menggunakan :

$$
\mathrm{K} 1(\mathrm{x}, \mathrm{y})=(\mathrm{K} 1(\mathrm{x}, \mathrm{y})+\mathrm{K} 2(\mathrm{x}, \mathrm{y}))=230+184=414 \approx 255
$$

$\mathrm{K} 2(\mathrm{x}, \mathrm{y})=\max (\mathrm{K} 1(\mathrm{x}, \mathrm{y}), \mathrm{K} 2(\mathrm{x}, \mathrm{y}))=230$

$K 3(x, y)=(K 1(x, y)+K 2(x, y)) / 2=(230+184) / 2=207$

$K 4(x, y)=\sqrt{ } K 1(x, y) * K 1(x, y)+K 2(x, y) * K 2(x, y)=\sqrt{ }(230 * 230)+\left(184^{*} 184\right)=230 \approx$ 255

Dengan melakukan pengecekan angka jika nilai angka >=128 maka nilai biner yang diberikan adalah 1 , jika angka $<128$ maka nilai biner adalah 0 . Maka nilai biner yang diberikan untuk angka $214=255$ adalah 1 .

3. Dalam pengujian aplikasi edge detection ini dilakukan dengan melakukan tes pengambilan citra dengan latar berwarna putih dengan tinggi latar $250 \mathrm{Cm}$. Obyek berdiri dari latar dengan jarak $20 \mathrm{Cm}$. Tinggi kamera $122 \mathrm{Cm}$, kamera yang digunakan canon 10 mega pixel dengan dudukan tripod. Jarak kamera dengan latar $227 \mathrm{Cm}$.

\section{Kesimpulan}

1. Aplikasi yang dirancang menggunakan metode sobel dapat digunakan untuk menggukur tinggi suatu benda dengan tingkat kesalahan yang kecil.

2. Jarak terbaik $20 \mathrm{~cm}$ dari latar ke obyek dilihat dari proses hasil tingkat kesalahan.

3. Semua kamera dapat digunakan dengan syarat memenuhi kriteria permintaan sistem operasi, driver software harus ada. 


\section{Daftar Pustaka}

Achmad Basuki, Jozua F. Paladin, dan Fatchurrochman, 2005, Pengolahan Citra Digital menggunakan Visual Basic, Andi Offset, Yogyakarta.

Balza Achmad, Kartika Firdausy, 2005, Teknik Pengolahan Citra Digital menggunakan Delphi, Ardi Group, Yogyakarta.

Bin Ladjamuddin, Albahra, 2005, Analisis Dan Desain Sistem Informasi, Graha Ilmu, Yogyakarta.

Bin Ladjamuddin, 2006, Rekayasa Perangkat Lunak, Graha Ilmu, Yogyakarta.

Darma Putra, 2010, Pengolahan Citra Digital, Andi Offset, Yogyakarta.

Mauridhi Hery Purnomo, Arif Muntasa, 2010, Konsep Pengolahan Citra Digital dan` Ekstrasi Fitur, Graha Ilmu, Yogyakarta.

T.Sutoyo, Edy Mulyanto, Vincent Suhartono, Oky Dwi Nurhayati dan Wijanarto, 2009, Teori Pengolahan Citra Digital, Udinus dan Andi Offset, Yogyakarta. 